\title{
ANÁLISE DE DISCURSOS DE GRADUANDOS
}

\author{
Sebastião Josué VOTRE (iD $\boldsymbol{\longrightarrow}$ \\ Universidade Federal do Rio de Janeiro (UFRJ) \\ Rosana da Silva BERG (DD \\ Centro Universitário Augusto Motta (UNISUAM) | Universidade do \\ Estado do Rio de Janeiro (UERJ)
}

\section{ఠ}

\section{OPEN ACCESS}

EDITADO POR

- Miguel Oliveira, Jr. (UFAL)

- René Almeida (UFS)

REVISADO POR

- Élcio Fragoso (UNIR)

- Iran de Melo (UFRPE)

- Nadia Azevedo (UNICAP)

- Bianca Walsh (IBGE)

SOBRE OS AUTORES

- Sebastião Josué Votre

Conceptualização, Análise Formal,

Investigação, Escrita- Rascunho

Original, Escrita - Análise e Edição.

- Rosana da Silva Berg

Conceptualização, Coleta dos Dados, Análise Formal, Investigação, Escrita

- Rascunho Original, Escrita - Análise e Edição.

DATAS

- Recebido: 04/02/2020

- Aceito: 24/09/2020

- Publicado: 23/11/2020

\section{COMO CITAR}

VOTRE, Sebastião Josué; BERG, Rosana da Silva (2020). Análise de discursos de graduandos. Cadernos de Linguística, v. 1, n. 2, p. 01-14

\section{RESUMO}

A proposta deste estudo é fazer análise de discursos de graduandos do primeiro semestre e contribuir para a formação de escritores competentes, guiando-os para recolher informações de textos, interpretá-las e recriá-las, por meio dos seus próprios textos. A metodologia adota a estratégia de recontextualização pedagógica do sociolinguista educacional Basil Bernstein, na qual o professor reformula os textos de modo a cooperar com o processo de aprendizagem dos alunos, a fim de que apreendam com propriedade o conhecimento proposto e produzam novos discursos. O referencial teórico apoia-se nos conceitos e propostas educacionais dos sociólogos Pierre Bourdieu e Bruno Latour e do linguista Norman Fairclough. Para este propósito, alguns conteúdos foram recontextualizados: o filme Encontrando Forrester e textos jornalísticos e acadêmicos sobre temas contemporâneos, como políticas públicas na educação, violência nos ambientes educacionais, racismo estrutural e representações sociais de estudantes sobre direitos humanos. A análise dos textos dos alunos mostra que eles mudaram suas práticas discursivas a partir do novo contexto em que atuaram.

\section{ABSTRACT}

The purpose of this study is to perform a discourse analysis of first semester students' speeches and thereby to contribute to the development 
of qualified writers by guiding them to collect information from texts, interpret and recreate them, through their own texts. The methodology adopted is the pedagogic strategy of recontextualization, formulated by the educational sociolinguist Basil Bernstein, in which the teacher reformulates the texts in order to cooperate with the students' learning process so that they properly apprehend the proposed knowledge and produce new discourses. The theoretical framework is based on the educational concepts and proposals by the sociologists Pierre Bourdieu and Bruno Latour and by the linguist Norman Fairclough. To that proposal some contents were recontextualized: the film Finding Forrester, as well as journalistic and academic texts on contemporary themes, such as public policies in education, violence in educational environments, structural racism, and social representations of students about human rights. The analysis of the students' texts shows that they changed their discourse practices after the new context in which they acted.

PALAVRAS-CHAVE

Análise de Discurso; Recontextualização Pedagógica; Capital Cultural.

\section{KEYWORDS}

Discourse Analysis; Pedagogic Recontextualization; Cultural Capital. 


\section{INTRODUÇÃO}

Este trabalho se produz no contexto da Atividade Prática Supervisionada - APS, que relaciona teoria e prática, sob orientação, supervisão e avaliação do professor, e que é realizada em grupos, com o objetivo de construir um processo de aprendizagem significativa, investindo na autonomia dos estudantes.

Um dos objetivos da APS é criar condições pedagógicas para que os estudantes se proponham buscar informações atualizadas, avaliá-las, criticá-las e organizá-las, com vistas à melhoria da qualidade de sua produção textual.

Com este objetivo em pauta, supervisionamos APS como componente da disciplina Leitura e Produção de Textos em uma universidade privada, na zona oeste da Cidade do Rio de Janeiro. A maioria dos estudantes que ingressam na instituição é formada por afrodescendentes, oriundos de camadas populares, com limitações na prática de leitura e com dificuldades severas na produção textual.

Nosso pressuposto é que, por apresentarem dificuldades na escrita acadêmica, os estudantes da disciplina leitura e produção de textos precisam de supervisão sistemática sobre como elaborar textos nos gêneros textuais mais exigidos na vida cotidiana, na academia e nas relações de trabalho. Não são raros os momentos do curso em que eles não conseguem produzir o texto solicitado no gênero exigido em determinada situação de comunicação. Quando conseguem, não demonstram as habilidades básicas de produção textual segundo as características desse gênero.

Neste estudo apresentamos e discutimos uma proposta de análise de discursos de graduandos do primeiro semestre universitário. A nossa atenção para o tema se dá em razão de, durante dezenas de anos de nossas carreiras, na graduação e nos programas stricto sensu, nos depararmos com déficit cultural e linguístico na produção de textos acadêmicos. Entendemos que faz parte de nosso ofício contribuir para formação de leitores e redatores competentes, ao orientá-los para lidar com os textos, recolher informações, interpretá-las e recriá-las, trabalhando como coautores dos textos associados a cada discurso. Para a superação do déficit cultural, recorremos às pesquisas e reflexões de Pierre Bourdieu, sobre os efeitos do contexto sociocultural das famílias no rendimento acadêmico de seus filhos.

Optamos pela postura de Bruno Latour, sobre a predisposição para ser afetado como condição para aprender de modo genuíno. E com vistas a contribuir para a formação de leitores e redatores críticos, apoiamo-nos na proposta de análise crítica do discurso, de Norman Fairclough, em que o autor sustenta que as mudanças sociais e as mudanças discursivas caminham juntas e que, ao assumirmos atitude crítica na formulação do discurso, contribuímos para a mudança social. 
A metodologia de seleção e apresentação de temas e, sobretudo, de seu tratamento, acolhe a abordagem conhecida como recontextualização pedagógica, que foi formulada pelo sociolinguista Basil Bernstein, como alternativa para superar o déficit linguístico de estudantes oriundos de camadas desprivilegiadas. Sua orientação é que o professor reformule os textos destinados ao ensino, de modo a cooperar com o processo de superação das dificuldades de leitura e escrita dos alunos, a fim de que eles apreendam com propriedade o conteúdo proposto nesses textos e produzam novos discursos relevantes.

As práticas de análise e de produção textual, neste primeiro estágio de interação com a variante linguística universitária, privilegiam gêneros discursivos com que os alunos estão mais familiarizados, e temas contemporâneos que são relevantes para eles, como manifestações de racismo e preconceito de cor, políticas públicas na educação, violência nos ambientes educacionais e representações sociais de estudantes sobre direitos humanos.

Optamos por trabalhar com textos motivacionais multimodais, sobretudo com filmes, em que se concentram imagens e recursos de narração, descrição e argumentação, e escolhemos filmes que focalizam desafios e superação nos recursos de escrita.

Nossa proposta de produção textual a seguir apresentada e analisada se concentrou no filme Encontrando Forrester, do diretor Gus Van Sant, que narra a história de Jamal, um garoto de 16 anos, negro, morador do Bronx, jogador de basquete, que tem talento para a escrita, e de William Forrester, escritor de prestígio, que vive, em certa medida, isolado do mundo.

Os dois se encontram e surge uma amizade entre o jovem com habilidade para escrita e o escritor veterano, que percebe o talento de Jamal e que o guia na estrada da escrita criativa. O filme suscitou debates acalorados e se transformou em foco de discussão e objeto de textualização.

Após assistirmos ao filme, promovemos debate sobre os temas tratados na história de Jamal e Forrester, com apresentação e discussão de textos motivadores, acadêmicos e jornalísticos. Os temas que mais causaram impacto nos alunos foram racismo contra negros, exclusão social e dificuldades no domínio da escrita padrão.

Concluída a fase de discussão, solicitamos que cada grupo escolhesse o tema que trataria em seu trabalho, e pedimos que dissesse qual a categoria de discurso que pensava utilizar, para desenvolver o tema. Alguns grupos tiveram dificuldade de estabelecer um gênero para apresentar o trabalho, mas após novo debate sobre os gêneros que mais dominavam, todos os grupos chegaram a consensos na escolha. O tema escolhido pelos grupos foi o racismo contra negras e negros.

A escolha deste tema, dado o perfil étnico e cultural dos alunos, sugere que eles estão particularmente sensíveis para as manifestações de preconceito racial, sobretudo associada à cor da pele. 
O resultado da atividade em grupo foi animador, com muitos trabalhos criativos. Cordel, rap, vídeos curtos, cartuns que recontam o filme e poesia foram alguns dos gêneros escolhidos.

Nos encontros seguintes com a turma, lemos e comentamos textos de vários gêneros que tratavam sobre o racismo, fazendo com que os estudantes expandissem seus conhecimentos sobre esse tema e começassem a dominar o discurso acadêmico.

\section{SUPORTE AO MÉTODO DE ANÁLISE}

Para suporte ao método de trabalho acolhemos a proposta de recontextualização pedagógica, de Basil Bernstein. O autor propõe que o professor reformule e, de certo modo, simplifique a estrutura e a formulação dos textos a fim de cooperar com o processo de aprendizagem dos alunos, para que dominem, com propriedade, as estratégias discutidas, e produzam novos discursos. Portanto, para Bernstein, cabe ao professor simplificar o modo de formular o conhecimento que, sozinhos, os alunos não elaborariam, nesses estágios iniciais da atividade redacional na universidade.

A ideia de recontextualização pedagógica aparece na primeira versão de $A$ estruturação do discurso pedagógico: classe, códigos e controles, e vai se detalhando em cada edição durante a vida do autor. Bernstein (1990) divide em três os contextos de discurso: primário, quando um texto é desenvolvido e posicionado num contexto; secundário, quando o discurso é reproduzido e o recontextualizador, quando há uma relocação do discurso. contexto recontextualizador é o nosso foco neste trabalho. Conforme o autor,

Quando um texto é apropriado por agentes recontextualizadores, atuando em posições desse campo, ele, em geral, sofre uma transformação antes de sua relocação. A forma dessa transformação é regulada por um princípio de descontextualização. Esse processo se refere à mudança no texto como se ele fosse primeiramente deslocadoe, depois, relocado. (BERNSTEIN, 1990, p.91)

Comentando o conceito de Bernstein, podemos dizer que ao apresentar as teses da dominação branca e da superação negra por meio da linguagem multimodal do filme, conseguimos com que os alunos compreendessem o que estávamos propondo. Os textos de apoio que leram apresentavam situações constrangedoras e alternativas controversas de lidar com o problema do racismo no Brasil.

A abordagem aqui adotada, com aplicação da ferramenta de recontextualização pedagógica decorreu de nossa consciência da falta de capital cultural e linguístico dos nossos alunos. Por isso optamos por trabalhar com as ideias de Bourdieu sobre reprodução do capital cultural e alternativas para ampliar esse capital. O autor adverte sobre a distância entre a língua utilizada na academia e nas diversas classes sociais. 
“(...) como (...) a linguagem universitária é muito desigualmente distante da língua efetivamente falada pelas diferentes classes sociais, não se pode conceber educandos iguais em direitos e deveres frente à língua universitária e frente ao uso universitário da língua (...)” (BOURDIEU, 2015, p. 62)

Os alunos com os quais trabalhamos chegam à universidade sem o domínio da escrita padrão, da linguagem universitária de que Bourdieu fala; em consequência disso, nos primeiros períodos são necessários projetos que os aproximem do uso padrão da língua escrita.

Não é certo que quem lê muito será um redator modelar, entretanto a leitura e o investimento em capital cultural colaborarão para escrita que vai se aperfeiçoando conforme a prática redatora se desenvolve.

Bourdieu postula que na escola e na universidade, os estudantes que absorvem e incorporam os modos, os ritos e os procedimentos dos bens culturais de mais prestígio ${ }^{1}$ têm mais chance de êxito, fazendo com que tenham mais e maiores oportunidades de sucesso pessoal, acadêmico e profissional.

O conceito de capital cultural incorporado foi formulado, testado e consolidado por Pierre Bourdieu.

\footnotetext{
"O capital cultural pode existir sob três formas: no estado incorporado, ou seja, sob a forma de disposições duráveis do organismo; no estado objetivado, sob a forma de bens culturais - quadros, livros, dicionários, instrumentos, máquinas, que constituem indícios ou a realização de teorias ou de críticas dessas teorias, de problemáticas, etc.; e, enfim, no estado institucionalizado (...)." (BOURDIEU, 2015, p. 82)
}

O perfil de nossos graduandos justifica trazermos para a cena o conceito de capital cultural de Bourdieu, uma vez que pretendemos que os graduandos avancem na produção textual e participem mais ativamente da vida acadêmica e profissional. Ampliar o capital cultural também contribuirá para que os graduandos se tornem leitores hábeis, o que contribui decisivamente para o desenvolvimento da sua escrita na língua padrão.

Os jovens das classes populares, além de não terem acesso privilegiado ao capital econômico, têm capital cultural exíguo, pois precisam trabalhar desde cedo, não lhes restando tempo para encontros acadêmicos como palestras, congressos, seminários, nem para atividades culturais como teatro, cinema e exposições que incorporem o capital cultural indispensável para competir com os mais aquinhoados. A formação de um capital cultural vasto e denso é parte do caminho para uma carreira acadêmica e profissional exitosa.

Além de recontextualizar os textos e de investir da ampliação do capital cultural, era preciso estimular nossos calouros para nossa proposta de produção textual; por essa razão acolhemos o conceito de reorganização do aprender, de Bruno Latour, em seu próprio texto e na interpretação de Maria Melo (2011), focalizando a ideia da disposição para ser afetado

1 Os bens culturais de mais prestígio são os valorizados pela classe hegemônica e, também são valorizados pela escola. Literatura, músicas, quadros, danças que pertencem ao cânone de uma cultura considerada culta. 
como condição para aprender. Segundo essa orientação do sociólogo e sua intérprete, é necessário criar mecanismos de aprendizagem e, sobretudo, condições ideais de produção, em que o aluno se disponha a ser afetado, e se prontifique a alterar sua própria dinâmica de trabalho, e assim interfira de forma relevante na realidade a sua volta. A disposição para ser afetado foi um traço dominante dos grupos, após assistir ao filme sobre a superação do jovem negro, em interação com o escritor branco. Com efeito, os textos que eles produziram contêm autocrítica, análise e avaliação dos preconceitos, e disposição para a luta, sob supervisão e orientação docente. Nos termos de Melo,

\begin{abstract}
A ideia de ser um entre outros, de afetar e de deixar-se afetar pelo que está ao redor, dá uma conotação política à questão das aprendizagens, implicando num compromisso de articulação do sujeito e seu mundo. A lógica das conexões vale igualmente para os sujeitos e suas fabricacões: para ser interessante e ter valor é preciso estar articulado, afetado por entidades cujas diferenças vão ser incorporadas de maneiras novas e inesperadas. (MELO, 2011, p. 182)
\end{abstract}

Conforme se pode constatar, conferimos peso redobrado à disposição para aprender, que o autor caracteriza como prontidão para ser afetado. Com efeito, só aprende, de forma efetiva, quem admite que não sabe e quer saber, no tópico que está em questão. Sobre a prontidão para aprender, Melo (2011, p.181) diz que o "sujeito é modificado/afetado quando aprende e o mundo também não será o mesmo depois da aprendizagem, pois terá sofrido uma tradução por aquele que aprendeu”.

Nas palavras de Latour:

\footnotetext{
Um sujeito desarticulado é alguém que, não importa o que os outros digam ou façam, sempre sente, age e fala a mesma coisa. [...] Por oposição, um sujeito articulado é alguém que aprende a ser afetado pelos outros - não por si próprio. (LATOUR, 2002, p. 03)
}

Seguindo essa orientação, trabalhamos temáticas que estão presentes no cotidiano do contexto imediato dos alunos, e que são de seu interesse, com o objetivo de que se envolvam com as temáticas, reflitam de forma mais densa sobre os temas e, aos poucos, se apropriem das práticas discursivas requeridas na universidade.

Recontextualizados, com foco em ampliar o capital cultural e afetados, os estudantes foram encorajados a refletir sobre como seus textos poderiam contribuir para mudanças sociais. Para tanto, introduzimos os alunos num modelo de análise crítica do discurso, examinando uma prática discursiva que revela uma prática social, conforme a proposta de Fairclough (2016). Tivemos êxito, pois os textos dos grupos indicam consciência crítica sobre as dificuldades de afrodescendentes se firmarem na escola e dominarem o capital cultural indispensável para competirem com os brancos no mercado de trabalho. Os textos permitem entrever revolta, resistência e, sobretudo, disposição para a conquista e o usufruto dos seus direitos.

Sobre os tipos de discursos que a educação, principalmente a universidade demanda, Fairclough diz: 
“(...) na educação, as pessoas encontram-se sob pressão para se envolver em novas atividades, que são definidas em grande parte por novas práticas discursivas (como marketing) e para adotar novas práticas discursivas em atividades existentes (como o ensino). Isso inclui 'relexicalizações" de atividades e relações - por exemplo, a relexicalização dos aprendizes como 'consumidores' ou 'clientes' de cursos como 'pacotes' ou 'produtos'. Inclui também uma reestruturação mais sutil das práticas discursivas da educação - os tipos de discurso (gêneros, estilos etc) que aí são usados - e a 'colonização' da educação por tipos de discurso exteriores, incluindo os da publicidade, os da administração e os da terapia”. (FAIRCLOUGH, 2016, p. 25)

Na graduação os estudantes são instados a participar das novas atividades de que trata Fairclough, para se adaptarem às novas exigências discursivas da universidade, fazendo uso da linguagem universitária a que Bourdieu se refere. A atividade linguageira está entre os desafios que a universidade apresenta para seus calouros que precisam textualizar suas ideias. Foi esse o nosso convite aos estudantes.

O trabalho com produção textual na universidade cooperou com o desenvolvimento do espírito crítico e para ampliação do capital cultural dos estudantes, uma vez que eles foram instados a pesquisar e discutir sobre as temáticas de que trata Encontrando Forrester, o que colaborou para avançarem na produção textual.

\section{CARACTERIZAÇÃO DA AMOSTRA}

A faixa etária de nossos alunos e alunas está entre 18 e 25 anos, que frequentam a graduação em direito no turno da manhã. A turma possui 32 (trinta e dois alunos, dezesseis rapazes e 16 moças), o que configura uma turma pequena para os padrões da universidade. São filhos da classe trabalhadora e moram na zona oeste da cidade do Rio de Janeiro. Há uma prevalência de estudantes que trabalham à tarde e à noite. Parte deles sai de plantões em hospitais ou na segurança pública para as aulas e parte sai das aulas para o trabalho. Há também os que cursam a graduação com o apoio financeiro das famílias ou com bolsas conquistadas do vestibular solidário que a instituição promove a cada semestre.

São estudantes que valorizam a conclusão do ensino superior, pois acreditam e desejam que a vida profissional colabore com seu avanço social e econômico. O que nos permite inferir que são oriundos de famílias de trabalhadores que têm um ethos que valoriza a educação como caminho para a ascensão social e econômica e como conquista da autonomia dos filhos.

Como não foi exigido um gênero específico, os estudantes demonstraram sua criatividade em gêneros que exigem trabalho artístico com a palavra, como o rape a poesia e com textos multimodais, como cordel e quadrinhos.

É relevante destacar que na turma há alunos e alunas que tocam instrumentos musicais de modo amador. No dia da apresentação dos trabalhos, havia violão e pandeiro nas 
apresentações de rap, estilo que surge nos anos de 1970, no Bronx, em Nova York, e que, portanto, está ligado à produção artística e cultural das periferias.

\section{ILUSTRAÇÃO DO DESEMPENHO NA ESCRITA}

Dadas as características deste trabalho, não vamos transcrever os textos produzidos pelos alunos em sua totalidade, e tampouco analisá-los um a um. Selecionamos passagens dos textos de cada grupo, com foco na temática, que é exclusão e preconceito racial, e oferecemos uma primeira análise global das mesmas. A escolha do tipo narrativo, como modo de apresentar a percepção dos grupos em relação ao preconceito ancora-se firmemente no filme, em que o mestre, Forrester, é branco, e o aluno, Jamal, é negro.

Conforme mostraremos a seguir, os estudantes criaram textos que não aceitam a realidade de exclusão dos negros e estabelecem propostas de superar a situação de baixa autoestima. Por razões de natureza didática, identificamos os grupos por letras do alfabeto. Registramos, para cada texto, o título proposto pelo grupo. Nos casos de quadrinhos, alteramos levemente a distribuição das falas, mantendo as características de diálogo, mas sem balões e sem imagens.

Cabe um comentário sobre os gêneros escolhidos pelos alunos para representarem suas ideias. Nossa orientação foi que poderiam escolher o modo que mais thes aprouvesse, para dar conta de suas ideias. Justificamos nossa atitude, por estarmos trabaIhando com alunos do primeiro semestre universitário, com pouca familiaridade com as exigências dos gêneros acadêmicos, uma vez que não foram ainda instados a produzir resumo, resenha nem relatório técnico de suas atividades. O fato de escolherem o rap denota o efeito do contexto sociocultural em que vivem, com manifestação forte dos movimentos de orientação hip-hop, nas batalhas de rimas, nas melodias de base em funk, e nos textos de autores consagrados, que escrevem melodias de análise crítica da realidade, a exemplo de Gabriel O Pensador.

O rap, estilo dominante no cancioneiro jovem, está presente em quase toda a produção, com alguns textos em estilo livre, poético. Compreende-se esta tendência rapista, uma vez que nos bairros e comunidades, ocorrem torneios de hip-hop, em que as batalhas de rimas desempenham papel central nas atividades culturais.

Alguns grupos trabalharam com cordel, o que indica manifestação das tradições nordestinas, fortemente presentes nas periferias da cidade do Rio de Janeiro. Apenas um grupo produziu reflexões em prosa e registrou citações que considerou relevantes.

Nos poucos excertos que selecionamos, procedemos a uma revisão leve, com atenção para a sintaxe padrão. 
Grupo A

Diálogo 1

Forrester - “(...) nem eu consegui passar...

(...) Fez orelhas no livro? Mostre um pouco mais de respeito pelo autor."

Jamal - "Já leu esse livro?"

Forrester - "Como disse?"

Jamal - "É seu, não é?"

"Foi você quem escreveu, não foi? Eu li o livro inteiro, nada mal, principalmente na parte que..."

Forrester- "Chega! A última coisa que eu preciso é de alguém me dizendo o que acha."

Diálogo 2

Forrester com o professor Crawford

- Licença, professor, posso ler algumas palavras?

- Sim, é claro, senhor.

- Obrigado. Meu nome é William Forrester.

Perder a família nos obriga a encontrar uma família. Nem sempre a família que é nosso sangue, mas a que pode se tornar nosso sangue...

Quando leio essas palavras de esperança e sonhos, eu me dou conta que o único desejo que foi garantido a mim tão tarde na vida, a dádiva da amizade.

- Senhor Forrester, posso perguntar a que devemos essa honra?

- Professor, eu falei aqui hoje porque um amigo meu não teve permissão. Um amigo que me protegeu, mesmo quando eu não quis. Seu nome é Jamal.

Testemunho do escritor Forrester

"Caro Jamal, alguém um dia escreveu que fugimos de nossos sonhos por medo de falhar; ou, pior ainda, por medo de ter sucesso. Eu sabia que você realmente realizaria seus sonhos, mas nunca imaginaria que realizaria os meus também. As temporadas mudam, meu jovem. E apesar de ter esperado até o último ano de minha vida para ver as coisas que vi neste último ano, não resta dúvida de que teria esperado uma eternidade, se não fosse você".

\section{Grupo B}

Rap(trecho)

- Sai daqui seu imundo

Foi o que disseram pra mim

Quando sentei do lado dum cara branquim

- Escuta, nunca desista dos seus sonhos, meu amor

Era o que minha mãe dizia com seu coração sofredor.

Muito Obrigado minha mãe por sempre cuidar da gente

Mas hoje tá difícil

Até pra negro ser atendente.

Olham pra gente e dizem:

- "Levanta e sai daqui".

Eu respondo: - "tudo bem, falou, desculpa ai"

Poema

O invisível é a cor mais forte

A cor mais forte é aquela que durante anos sustentou valores deturpados,

um grande surto não embasado. Das nossas raízes fomos tomados, pelo vulgo mais racional dos homens, em maior parte da história, errado.

(...)

Vivendo pela primeira vez desde a partilha de nossa terra, sobreviver apenas, já não é mais do nosso interesse. Julgados a cada passo, vamos retomando laços, brigando por espaços que não deveriam ser disputados.

Grupo C - Cordel

A história de Jamal

Em um pequeno bairro da periferia, 
Um pobre rapaz negro tinha moradia.

Na escola onde estudava, sempre se destacava,

Seu desempenho escolar não se comparava.

Em uma brincadeira de criança, uma casa ele invadiu.

Após um susto o proprietário lhe dar,

Saiu correndo e sua mochila esqueceu por lá.

Ao voltar para recuperar seu objeto,

Deu uma de esperto,

Pediu desculpas ao senhor ranzinza que o assustou

E pela sua história Jamal se interessou.

No mesmo dia que fez essa incrível amizade

Logo recebeu uma grande oportunidade:

Estudar em uma escola particular,

Tendo a chance de a sua vida mudar.

Grupo D - Rap (trecho)

As margens em que eu vivo

No mundo em que vivemos não era para existir diversidade

Quem me dera se ao menos houvesse liberdade

Liberdade de ser quem somos

Liberdade de viver com menos preconceito

Ser negro não é vergonha, vergonha é ter preconceito

Não tenho outros interesses, aceita que eu sou inteligente

Só porque sou negro, não quer dizer que sou impotente

Ser negro é lutar, lutar e nunca parar

É seguir adiante sem nunca recuar

É viver numa sociedade cheia de preceitos e preconceitos

E mesmo assim nunca desistir do seu direito.

Grupo E - reflexão

A importância da escrita

A escrita vem para garantir o registro das ações e pensamentos humanos; ela foi se desenvolvendo e ganhando extrema relevância nas relações sociais, na difusão de ideias e informações.

"A prática da escrita não deve ficar restrita a estudantes, nem tampouco aos que dominam a forma culta, como os escritores. Escrever vai muito além das regras impostas por qualquer sistema teórico ou didático: é um modo privilegiado de se descobrir e desvelar humanamente a experiência imperdível de viver" (https://brainly.com.br/tarefa/10251644)

\section{ANÁLISE DA PRODUÇÃO DOS ALUNOS}

Após leitura crítica da produção dos alunos sobre a temática do racismo, destacamos que:

- Os alunos manifestam visão aguda, e radical, em relação à discriminação e ao preconceito com que convivem. Aguda, porque expressam o que sentem no corpo e no espírito, uma vez que são vigiados e punidos, por serem negros. Neles, mais do que em outras categorias étnicas brasileiras, cumpre-se a máxima de vigiar e punir, como Foucault descreve no passado; no caso desses alunos, vigilância e punição se dão no presente, contemporâneo. Radical, porque resulta de fatos, de barreiras de raiz, de restrições 
físicas, com que se deparam nos espaços públicos e privados, nas igrejas, nos clubes e nos espaços culturais.

- Apresentam descrição densa dos contextos de humilhação e opressão; tal densidade se reflete nos registros da memória, das tentativas de diálogo, da desautorização para assumirem seu próprio discurso.

- Formulam estratégias iniciais de resistência e enfrentamento do quadro opressor; essas estratégias fundam-se nos exemplos do personagem negro do filme e na presença de líderes intelectuais apresentados no filme que, além da etnia, estão centrados nos valores humanos de cada cidadão.

- Trabalham, de forma consistente e consciente, para fundar espaços de cidadania reclamada, a que se conquista, no processo de reclamação constante, com julgamento, denúncia, e com vontade indomável de vencer.

\section{CONSIDERAÇÕES FINAIS}

O trabalho nos permitiu inovar na utilização de gêneros do cotidiano dos alunos. Constatamos que a noção de gêneros textuais e suas classificações, que têm sido frequentemente objeto de estudo, não é relevante neste estágio em que estão os alunos. Se é verdade que o êxito escolar dependerá do domínio e da habilidade de ler e produzir com proficiência em gêneros acadêmicos e profissionais, no primeiro momento de textualização na universidade os alunos precisam de liberdade de escolha do modo de redigir.

O objetivo de despertar nos alunos a consciência da importância de refletir sobre os temas que os incomodavam foi alcançado, pois eles se aplicaram na leitura de textos de suporte à temática do racismo e discutiram com seriedade sobre a realidade brasileira, sobretudo a respeito das barreiras que encontram para prosseguir em seus estudos e conquistar espaço digno no mercado de trabalho.

O objetivo de trabalhar a escrita também foi alcançado, comprovando que o êxito da tarefa está relacionado à aplicação das estratégias de recontextualização pedagógica, no sentido de Basil Bernstein, e na criação de um contexto favorável para a manifestação da prontidão para aprender, no sentido que Latour utiliza para o conceito de prontidão para ser afetado. Os estudantes criaram textos originais em que está evidente que eles não aceitam a realidade de exclusão dos negros e estabelecem propostas de superar a situação de baixa autoestima. 
Para produzirem seus textos, além de assistirem ao filme Encontrando Forrester e lerem o cardápio de textos que selecionamos, os estudantes aprofundaram-se nas temáticas sobre as quais escreveram com o objetivo de conhecer mais sobre os assuntos que abordaram em sua produção escrita. Essa investigação fez com que os calouros ampliassem o capital cultural de que Pierre Bourdieu fala, o que contribuiu para uma escrita que avançou na incorporação do capital cultural requerido tanto pela universidade, quanto pelo ambiente profissional.

O trabalho de leitura e produção textual ampliou os conhecimentos dos estudantes sobre questões que os incomodam, fazendo com que eles, os estudantes, pesquisassem textos que discutissem a não aceitação da realidade de exclusão dos negros.

A adesão dos alunos na busca de temáticas relevantes para seu cotidiano, e o envolvimento nas leituras de textos relacionados a essas temáticas confirmou a universidade como o espaço da reflexão; permitiu-nos entender também que não existe escrita sem reflexão.

No início do trabalho, alguns alunos acreditavam que, por estarmos na era da informação, escreveria melhor aquele que acumulasse um maior número de dados e de informações. Com o desenrolar da atividade, concluíram que é necessário não só acumular dados e informações, é necessário analisá-los e interpretá-los a fim de fazer uma apresentação com mais clareza e mais eficiência aos que vão ler os textos que eles produzirem.

Os estudantes constataram que sem reflexão a escrita tem pouca chance de avançar e que estavam dando um primeiro passo para começar a trilhar a estrada de outros gêneros textuais, sobre temáticas que estivessem mais distantes no dia a dia deles. Nesses gêneros estão inseridos os acadêmicos.

Portanto, concluímos que a produção textual na graduação merece investimento reflexivo que resulte em empoderamento do estudante bem como em sua autonomia, uma vez que é exigência do mundo acadêmico e do mundo do trabalho o domínio tanto do modo oral, quanto do modo escrito da língua.

Em síntese, o que constatamos, neste primeiro estágio de trabalho na linha de nossa proposta de trabalho com alunos oriundos de classe sociocultural desprivilegiada, é que o referencial acolhido e a proposta pedagógica da recontextualização favoreceram a leitura crítica e a produção consistente de textos, em que os autores se constroem como cidadãos envolvidos e engajados com a luta por seus direitos fundamentais.

\section{REFERÊNCIAS}

BERNSTEIN, Basil. A estruturação do discurso pedagógico. Petrópolis: Vozes, 1990. 
BOURDIEU, Pierre. Os três estados do capital cultural. Tradução de Magali de Castro. In: NOGUEIRA, Maria Alice; CATANI, Afrânio. Escritos de educação. Petrópolis: Vozes, 2015. p. 80-88.

FAIRCLOUGH, Norman. Discurso e mudança social. Brasília: UnB, 2016.

LATOUR, Bruno. Reflexão sobre o culto moderno dos deuses fe(i)tiches. Bauru, São Paulo: EDUSC, 2002.

MELO, Maria de Fátima Aranha de Queiroz e. Discutindo a aprendizagem sob a perspectiva da teoria atorrede, 2011. Disponível em: http://www.scielo.br/pdf/er/n39/n39a12.pdf Acesso em: 27 jan. 2020. 